his power in so far as he is the producer and Lord of all things, in this third Book we have still to deal with his perfect authority or majesty (dignitate) in so far as he is the end and governor of all things. 40 (1.1867a)

The chapters of Book III, then, must cover both those aspects of divine providence: God as the ultimate goal of all created existence, and God's variously directing all things toward the goal that is (somehow) himself.

Therefore, we will have to proceed in the following order, so as to deal, first, with God himself in so far as he is the end of all things [chaps. 2-63]; second, with his universal governance, in so far as he governs every created thing [ chaps. 64-110]; and, third, with his special governance, in so far as he governs creatures that have intellect [chaps. 111-163]. (1.1867b)

We will, of course, find subdivisions within those three broad topics as we go along. For now, it will be enough to provide a preliminary sketch of the subdivisions in the first of them. In III.2-15, Aquinas begins the development by focusing on the concept of an end or goal, which he analyzes as necessarily involving goodness, a result that seems to lead him to examine the apparent prevalence of various sorts of badness in the goals and developments of created things. In III.16-24 he undertakes to explain just how God himself is to be considered the ultimate goal of things in general. In III.25-37, he argues for the central importance of human beings' intellective cognition of God in their achieving the ultimate goal of human existence, and in III.38-47, he explores various conditions that he argues must apply to human cognition in those special circumstances. Finally, in III.48-63, he concludes his development of the first of those three grand topics by trying to show just how an intellective cognition of God is the principal ingredient in ultimate human happiness.

\title{
II. AGENTS, ACTIONS, AND ENDS
}

\section{Thoroughgoing Teleology}

Aquinas concludes his introductory chapter by announcing that his first task in Book III, a task to which he devotes sixty-two chapters, is to investigate "God himself in so far as he is the end of all things" (1.1867b). That compressed description of a very big topic is likely to arouse some misgivings. Why should we think that absolutely all things do have ends or goals? Even if we're given good reasons to think that they do, why should we think that all those ends or goals converge in a single end for all things? And even 
if we should be convinced of that, why should we think that that single universal end must be identified (somehow) as God himself?

So it is encouraging to find Aquinas showing, in the opening sentence of his second chapter, the first substantive chapter of Book III, that he himself thinks that his compressed description requires him to begin by addressing the first of those misgivings: "T herefore, the first thing we have to show is that every agent in acting does intend some end" (2.1868). The foundational importance of this teleological thesis to all the rest of Book III calls for a close look at Aquinas's development and defense of it.

The fact that he uses the words 'agent' (agens), 'acting' (agen do), and 'intend' (intendit) in expressing the thesis may suggest that he is construing it too narrowly for it to be considered a claim about all things. But it soon becomes clear that in this context, he is using those terms in technically broad senses, such that an agent will be absolutelyanything considered asthe active subject of any sort of movement or change, from a person's making a choice to a fire's hardening a clay pot, and such that 'intend' (and 'intention') will apply not only to a person's plan for coping with certain circumstances but also to fire's propensity for hardening clay in certain circumstances. ${ }^{41}$ Still, however he may go on to justify extensions of those notions, the paradigms of agency, acting, intending, and ends are of course to be found in the deliberate behavior of intellective beings, "things that are obviously acting for an end" (2.1869). For that reason Aquinas borrows the language of his broader descriptions from the way we talk about the manifestly purposive activity of beings like us. $\mathrm{H}$ is first examples are a doctor acting to restore a patient's health, and a runner running toward a definite goal. In obser ving how we talk about such cases he presentshisinitial account of an end: "we say that the end isthat toward which the agent's impetustends, since we say that an agent that attains that attains its end, while one that falls short of it we describe as falling short of its intended end" (2.1869). 42

As a consequence of that account of an end, presented in unexceptionable broad observations regarding the clearest cases, Aquinas considers himself entitled immediately to extend the use of 'end' into explanations of the activities of a bigger class of things. The plausibility of the extension is enhanced by the fact that the passage introduces the notion of an end in language that isn't restricted to intellective agents. And so, he says, "it makes no difference in this respect whether that which tends toward an end is cognizant [ of it] or not; for just as the target is the archer's end, so is it the end of the arrow's motion" (2.1869) - that is, so is it that toward which the arrow's impetus tends. 43 In Aquinas's project of showing that every thing considered as an agent acts for an end, incognizant agents are obviously going to make up the biggest and most obviously problematic class. Consequently, it's important to decide just how much bigger a class of things can legitimately be included already, as a result of this very simple move. The archer joins the doctor and the runner as a paradigmatic agent obviously acting for an end. And if we focus on the feature of this new example that 
makes the extension plausible, it seems that the only extension warranted so far is limited to just such incognizant things as are obviously directed by cognizant agents. On that basis, the doctor's ointments and the runner's shoes could join the archer's arrows in the newly broadened class of things that may be said to act for ends. But admitting incognizant instruments deliberately employed by undoubtedly cognizant agents in order to achieve their conscious goals is of course still a long way from accepting, say, a forest fire started by lightning as the sort of thing that in its acting intends an end.

Aquinas's move to include incognizant instruments among agents that in acting do intend some end might suggest that the main purpose of this first argument is to provide support for the universality of the teleology thesis by expanding the class of things that can count as agents whose activities are reasonably explained in terms of ends. He does return to providing that sort of support later in the chapter, but it turns out that this initial expansion-from intellective agents alone to intellective agents and their instruments-is all that he wants along that line for now. What concerns him more at this stage (2.1869-1872) is clarifying and expanding the notion of an end.44 But, of course, the acceptability of the thesis depends as much on what's meant by 'end' in it as on expanding the class of things that can be recognized as acting for ends. Since the ends of agents' instruments in their acting are identical with the ends of the agents themselves in their acting, 45 Aquinas's first expansion of that class hasn't required recognizing as ends any things, events, or states of affairs beyond those we ordinarily recognize as ends. And, of course, his teleology thesis will be much stronger if he can develop and defend it without radically altering the sense or reference of any of the crucial terms that make it up.

$\mathrm{H}$ aving provided several examples of both cognizant and incognizant agents whose actions are to be explained in terms of definite ends-healing the patient, crossing the finish line, hitting the bull's-eye-Aquinas turns his attention for a moment to the definiteness of those ends, and generalizes at once to the definiteness of every end of every sort of agent:

Now every agent's impetus tends toward something definite (certum), since not just any action proceeds from any given power, but heating from heat, of course, and cooling from cold. It's for that reason, too, that actions differ in their species on the basis of the variety of active [powers]. (2.1869)

'Every agent's impetus tends toward something definite' has the look of a strong claim, but I think that the perfunctory support Aquinas provides for it helps to show that what he actually intends to claim here is weak to the point of being truistic. Any agent engages in a certain sort of action only if and only to the extent to which it possesses an active power the exercise of which is a necessary condition for its engaging in an action of that sort. The fire on the hearth warms the room not because of its active powers of 
lighting space or consuming fuel but just because of its active power of heating air, which is the only possible source of that sort of action on the part of that sort of agent.46 The specification of any action on the part of any sort of agent entails that agent's possession of an active power of the appropriate sort. This truistic conclusion constitutes Aquinas's first clarification of the notion of an end.

And he goes on at once to clarify it further, ending this first argument by introducing a distinction between kinds of ends:

Now an action sometimes [A] terminates in something that is brought about (factum)-e.g., building terminates in a building, healing in health; but sometimes [B] it doesn't-e.g., intellective and sensory activity. And if $[A]$ an action does indeed terminate in something that is brought about, then the agent's impetus tends, through the action, toward the thing that is brought about; while if [B] an action doesn't terminate in anything that is brought about, then the agent's impetus tends toward the action itself. Therefore, every agent, in acting, must intend an end: sometimes, indeed, [B] the action itself, but sometimes [A] something that is brought about through the action. (2.1869)

Before evaluating this last part of the first argument, I want to say something about the unusual character of the whole argument. Although Aquinas presents it and the chapter's other arguments as if they were so many alternative sources of support for the chapter's thesis, and although their conclusions are or contain restatements of the chapter's thesis (as would be expected in arguments of that sort), and although each of them does in some way or other support some aspect of the thesis, several of them, including 2.1869, are more importantly presenting clarifications of the notion of an end and thus clarifications of the thesis. Each of these arguments makes its own contribution(s) to the clarification process or offers further support for a clarification made in a preceding argument, and so we can't simply focus on what we take to be the strongest one or two among them. Appreciating all that this first argument has to offer as support for the teleology thesis is easier if we give the argument a conclusion more complex than the one Aquinas provides for it (quoted above)-perhaps something like this: Therefore, every agent, not merely intellective agents but their incognizant instruments as well, in acting, whether primarily or instrumentally, intends, or in its impetus tends toward, some end, which must be something definite, and which can be either something brought about by the agent's acting or the acting itself.

In order to achieve any end, an agent must engage in some action. And so an end of type A, the type in connection with which the notion of an end is probably most familiar, can be construed technically as an ulterior end, one to which the agent's impetus tends "through the action." Paradigms of type A will involve actions that are naturally necessitated or deliberately 
designed to terminate in specifically definite results-for example, fire's hardening clay, or your going to the store for groceries. On the other hand, intellective or sensory activities, Aquinas's paradigms of type B, are so flexible in nature and so nearly constantly engaged in, willy-nilly, that they can't be considered to be naturally necessitated to terminate in any predetermined set of specifically definite results. But they can of course be deliberately designed to terminate in something that is brought about: you may look in order to find your keys, or think in order to choose among the vegetables in the store. Furthermore, thought and sensation are often, probably most often, engaged in for their own sakes, or at least not for the sake of any definite result. So, at least sometimes, such activities as looking and thinking are engaged in without any ulterior ends- that is, as immediate ends in their own right and as ends that are also ultimate, at least in the sense of serving no ulterior purpose.

\section{Ultimate Ends}

Aquinas's Chapter 2 is the beginning of his detailed investigation of a large-scale topic: God considered as the universal end of created things. When the chapter's teleology thesis is viewed in the light of that topic, we can see that ever y agent will have to turn out to intend not merely some end of its own but one and the same end, which will have to turn out (somehow) to be God himself. And if that extension of the thesis is to have any hope of being taken seriously, it will have to be interpreted as a claim about God not as the immediate but rather as the single ultimate end of all creaturely activities. It seems fair to say that we have no reliable evidence that God is in any way the immediate goal of anything that creatures do, aside from religious activity. Besides, we've already seen Aquinas expressly describing God as creatures' ultimate goal. 47 For those reasons, it's especially important for Aquinas's development of his thesis, even before God has been explicitly reintroduced into it, that he examine the concept of an ultimate end and add it to the aspects of ends he will need as this investigation develops.

$\mathrm{He}$ starts that examination with a definition illustrated in terms of paradigmatic agents and ends:

as regards all things acting for an end, we say that the ultimate end is that beyond which the agent doesn't seek (quaerit) anything else. For instance, the doctor's action continues right up to [the patient's] health; but when that has been achieved, he doesn't try for (conatur) anything further. (2.1870)

This is clear and unobjectionable, as long as we understand that the ultimacy that's being defined and illustrated here must be thought of as relative (1) to agents ( since health as Aquinas introduces it here will not also be a 
builder's ultimate end ${ }^{48}$ ) and should probably be thought of as relative al so (2) to agents' other ends- that is, as that beyond which the agent doesn't try for anything further in one particular line of en deavor, rather than at all.49 A doctor's action, considered just as such, could have no goal beyond his patient's health, but the intellective agent who happens to be the doctor will surely have personal goals that lie beyond the health of any and every patient of his (and will almost surely have goals beyond his own health). $\mathrm{H}$ ealth is the undoubted, absolutely ultimate end of a doctor's actions considered only as medical actions definitive of doctoring. But Aquinas, perhaps ignoring the fact that the ultimacy introduced here isn't absolute, argues for its universal application:

in connection with the action of any agent at all there must be found something beyond which the agent doesn't seek anything else, since other wise actions would tend to infinity- which is of course impossible. For [if actions did tend to infinity] an agent would not begin to act, since it is impossible to get through infinitely many. 50 For nothing is moved toward that at which it is impossible to arrive. Therefore, every agent acts for an end. (2.1870)

Despite its conclusion's simplified restatement of the chapter's thesis, this argument seems designed to support the new claim that every agent acts for an ultimate end. But, in any case, the argument is flawed. It looks as if it's meant to be based on a Zenonian can't-get-started paradox, like the one in which the runner can't get to the goal without running half the distance and, moreover, can't get to the halfway point without running a quarter of the distance, and so on.51 What Aquinas actually presents here, however, seems to amount to no more than a case of won't-get-started-if-theimpossibility-of-arriving-is-acknowledged. After all, many people tried to square the circle or to build a perpetual-motion machine. It seems plainly false that "nothing is moved toward that at which it is impossible to arrive," even if no rational person, considered just as such, is moved toward attaining what that person acknowledges to be unattainable.52 And as for "it is impossible to get through infinitely many," its applicability here is at least dubious. Why shouldn't an agent discover unforeseen successive ultimate ends, especially if ultimacy is understood as Aquinas introduces it here? All $S$ wants is one million dollars, and he doesn't try for anything further, and when he gets it he's satisfied-for a while, after which he decides that now all he really wants is two million dollars, and so on. 53 Obviously, such relatively ultimate ends could in theory go on ad infinitum successively, but that sort of progression of infinitely many goals needn't prevent or even deter any agent from getting started. All that would be definitely ruled out by infinity of this sort is the possibility of total, final success. And if this argument is supposed to apply to non-intellective agents, too, it shows signs of an analogous sort of failure. For although Aquinas thinks of getting to 
the center of the earth as an ultimate end for every terrestrial body, and although every one of them is indeed moved toward the center of the earth, any body's actual arrival at the center of the earth is a real impossibility. 54

The concept of an ultimate end is important enough for Aquinas's purposes that he offers two more arguments in support of its universal applicability. The first makes use of the distinction between ends of type A-things, events, or states of affairs brought about by actions- and ends of type B-actions themselves.

If an agent's actions do go on ad infinitum, then it must be that either something that is brought about follows from those actions or not. If something that is brought about does follow, then of course its existence will follow after infinitely many actions. But it is impossible for anything to be if it presupposes infinitely many, since it is impossible to get through infinitely many. But what cannot be cannot be brought about, and nothing can bring about what cannot be brought about. Therefore, it is impossible that an agent begin to bring about something for which infinitely many actions are presupposed. (2.1871)

This part of the argument, dealing with ends of type A, could be adapted to provide solid support for the claim that no agent could succeed in bringing about something for which infinitely many actions are presupposed-if there were any purpose to be served by supporting such a claim. But, for reasons brought out in considering this argument's immediate predecessor, it can't support its conclusion about the impossibility of an agent's beginning such a process. And so this part of the argument doesn't show us that every agent, or any agent, must have an ultimate end of type A.

The rest of the argument does no better as regards ultimate ends of type B:

If, however, something that is brought about does not follow from those actions, then the ordering of the actions must be either [1] in accordance with the ordering of active powers-e.g., if a person senses in order to imagine, and imagines in order to think (intelligat), and thinks in order to will-or [2] in accordance with an ordering of objects-e.g., I consider the body in order to consider the soul, which I consider in order to consider a separated substance, ${ }^{55}$ which I consider in order to consider God. (2.1871)

I'm interrupting this second part of the argument here in order to raise a question. Aquinas provides no basis at all for his very strong claim that only these two kinds of orderings - of active powers and of objects-are available as bases for the ordering of actions. But even if we leave that claim unquestioned, we can raise a question about the second ordering. Why shouldn't I consider the body in order to consider the soul, and then find myself led by that consideration to a better-informed consideration of the body, which 
leads to a better-informed consideration of the soul, and so on, back and forth, indefinitely? This argument is al ready in trouble, and it gets worse.

\begin{abstract}
But one cannot go on ad infinitum, whether [1] regarding active powers, . . .56 or [2] regarding objects (just as not regarding beings, since, as was proved earlier [ in I.42], there is one first being). Therefore, it is not possible that actions go on ad infinitum. Therefore, there must be something such that the agent's striving (conatus) comes to rest in the possession of it. Therefore, every agent acts for an end. (2.1871)
\end{abstract}

As for [1], Aquinas's philosophy of mind provides an elaborate rationale for the ordered list of active powers that plays a crucial role in this argument, but I see no reason why the ordering and the finiteness of that list should entail that your own cognitive and volitional acts must follow that order and come to a stop when they reach volition.57 Aside from the kind of objection I've already raised, why shouldn't you sometimes follow just that order, but then will to sense-in order to imagine, and so on, round and round, theoretically ad infinitum? Although the case made here for the finiteness of a series of actions based on [2] an ordering of objects isn't much better in its details, it has the advantage of including God himself as the object beyond which cognitive and volitional activities really cannot find another. At this stage of SCG no additional argument is needed for the claim that God is the single ultimate end of intellection, but that claim is certainly not all that this argument is out to show, and what else it aims at it misses.

Aquinas's third and last argument concerned with ultimate ends in this chapter is no more successful than the other two, and it provides grounds for a further misgiving. "In connection with things that act for an end, all the intermediaries between the primary agent and the ultimate end are ends in respect of those that precede them and active principles in respect of those that follow them" (2.1872). The further misgiving is stirred by this universalized observation, which seems to imply a simple linear depiction of any individual's active principles and ends. Because of the way Aquinas introduced the concept of ultimacy in this context, and because there are no definite (or indefinite) articles in Latin, it's not quite clear whether he's assigning exactly one ultimate end to each thing that acts for an end (although of course 'ultimate' strongly suggests 'unique'). 58 But if he is, then he seems to be claiming that a successful agent's entire goal-oriented career, from beginning to end, is depicted in a schema as simply linear as this ( where ap = active principle) : 59

$$
\text { ap } \rightarrow \text { action } \rightarrow \text { end/ ap } \rightarrow \text { action } \rightarrow \text { end/ ap } \rightarrow \text {. . ultimate end. }
$$

But, of course, it's much more plausible that the depiction of an agent's goal-oriented career requires a schema characterized by forking paths and 


\section{NORMAN KRETZMANN}

parallel lines-that is, that not every achieved end is transformed into an active principle giving rise to progress in just one direction. Short-run sequences of this sort are very familiar: a need for food leads you to shop, the groceries provide the basis for making a meal, the prepared meal provides an occasion for eating. But while shopping, you're thinking about going to a movie that evening, and while the meal is being made, you're talking with your spouse about a movie to go to- and so on, and so on. Nonetheless, Aquinas ends this argument by relying on the already challenged rigidity of his ordered list of active powers or principles in order to draw what seems to be a truncated conclusion:

Therefore, if an agent's striving is not directed toward anything determinate (determinatum), but its actions go on ad infinitum, then active principles must go on ad infinitum. But that's impossible, as was shown before. Therefore, it is necessary that an agent's striving be directed toward something determinate. (2.1872)

Apart from problems I've al ready raised about Aquinas's use of his list of active principles in this connection, I don't see why any impossibility should attach to an infinite progress of active principles, which is all that's at issue here. And I'm a little puzzled by his focusing in this conclusion not on the ultimacy of ends but on their determinateness, which I take to be the same as the definiteness he's already argued for (in 2.1869).

If, as seems fairly clear, Aquinas's aim in these three arguments $(2.1870-72)$ is to show that agents have to have ultimate ends, he would have done better to make prominent use of a simple, well-known Aristotelian line of thought that appears in these arguments only in a parenthetical reference. 60 The fact that he uses that line effectively in SCG I makes it seem only odder that he doesn't use it here as well:

In the case of any willer, what is principally willed is a cause of [the willer's] volition. For when we say 'I want to walk in order to be healthy', we consider ourselves to be indicating a [final] cause; and if someone asks 'Why do you want to be healthy?', we will go on assigning causes until we arrive at the ultimate end, which is what is principally willed, which is [in turn] a cause of volition altogether on its own.61 (74.635)

\section{3. $N$ atural Agents, Likeness, and Efficient Causation}

Although Aquinas's claims about ends must eventually suit explanations of all sorts of actions by all sorts of agents, he understandably develops most of what he has to say about them (in 2.1869-72) in terms of the efforts, powers, objects, and aims that we know best-those that are most readily, or exclusively, associated with human beings. H owever, since the chapter's teleology 
thesis - "every agent in acting does intend some end" - needs support most obviously in respect of its universality, it's not surprising that he also devotes part of the remainder of the chapter to a further and much more sweeping expansion of the class of agents, things whose activities are reasonably explained in terms of ends. He argues now for including within that class not merely intellective creatures and their nonintellective instruments but al so all "natural agents," all the way down through olive trees to fires.

Every agent acts either through its [nonintellective] nature [alone] or through its intellect. Now as regards those that act through intellect, there is no doubt that they act for an end. For when they act, they preconceive in intellect what they achieve through action, and they act on the basis of that sort of preconception. That's what it is to act through intellect. (2.1873)

In opening the argument with this brief review of the paradigmatic sort of agent, Aquinas introduces an account of paradigmatic intention: an agent's intellective preconception of what is to be achieved through the agent's action. It is entirely plausible that such a preconception should involve a projected likeness of the intended result, but what Aquinas infers from that feature of paradigmatic intention needs some explaining and defending.

Now just as in a preconceiving intellect there is a whole likeness of the effect that is [ to be] arrived at through the intellective agent's actions, so in a natural agent there pre-exists a natural likeness of the effect-a likeness by which the action is determined to this or that effect. For a fire generates a fire, and an olive tree generates an olive tree. Therefore, an agent that acts through its [nonintellective] nature [alone] tends toward a determinate end through its own action just as an agent that acts through intellect does. Therefore, every agent acts for an end. (2.1873)

The argument's casual assimilation of a natural agent's substantial form to an intellective agent's preconception can seem exaggerated, but all Aquinas really needs here is a rough analogy between kinds of likeness, intellective (or imagined) and natural. And as long as the natural action at issue is reproductive generation, one thing's generating another thing of the same kind, it's not unreasonable to present a natural agent's substantial form as a likeness that determines the effect-not a preconception, of course, but a species-specific prefiguring. But reproductive generation is only one sort of natural action. A fire doesn't only start other fires, it also brings about hardness in clay and softness in wax; and neither hardness nor softness appears to be an aspect of fire's substantial form. Does Aquinas suppose that fire somehow contains likenesses of hardness and softness as well? Yes, he 


\section{NORMAN KRETZMANN}

does. The wayhe doesso and hisgroundsfor doing so are spelled out in Book I, but they're essential to his theory of efficient causation and so worth reviewing here in con nection with the development of histheory of agency. 62

In several places Aquinas develops a general account of kinds of likeness, 63 beginning with the basic obser vation that if $X$ can literallyand trulybe said to be like $Y$ in any way at all, then $X$ has some form that $Y$ al so has. ${ }^{64} \mathrm{Fun}$ damentally, then, likeness is con -formity, partial sameness in respect of somehow sharing at least one form. Likeness shows up in many different contexts, of course. But our present concern is solely with likeness in connection with efficient causation or agency, cases in which the preconceived or prefigured effect is also thought of as the end for which the efficient cause, conceived of as an agent, acts. We can, then, focus exclusively on Aquinas's analysis of the kinds of likeness obtaining between an efficient cause and its effect.

$\mathrm{He}$ thinks of efficient causation as one thing's (natural or artificial) production of another thing, or event, or state of affairs. He understands this in terms of an agent's (or active subject's) initiating the sharing with a patient (or passive object) of some form the agent possesses antecedently, often in some way quite different from the way in which the patient comes to possess the shared form. (Because I'm adopting Aquinas's understanding of efficient causation for present purposes, I'll write in terms of 'agent causation.' 65 ) Some sort of likeness between an effect and its cause is an immediate consequence of this notion of agent causation, since agent causation shares a necessary condition with likeness: If $A$ is the agent and $P$ is the patient, then $A$ antecedently somehow has some form, $f$, that $P$ also somehow has, consequently - even where $A$ is a fire, $P$ is a clay pot, and $f$ is hardness. In agent causation the effect that is brought about by A's exercise of some active power is the informing of $P$ with $f .66$

Agent causation, then, entails a con-formity between cause and effect:

Since ever y agent does something like itself insofar as it is an agent, but each thing acts in keeping with a form belonging to it, it is necessary that there be in the effect a [ consequent] likeness of a form belonging to the agent. (ST Ia.4.3c)

Clearly, 'likeness' ( similitudo) isa technical term in thiscontext, closer to 'correspondence' than to 'resemblance' in the ordinary sense, even if in some cases the correspondence may be detailed enough to count as resemblance. The only immediately relevant con-formity between an agent cause and its effect is the presence in the effect of characteristics that could serve to identify or at least to type the agent- physical or metaphysical clues providing the basisfor an inductive argument to some aspects of the agent's nature.

Agent causation does not include the generation of accidental effects, effects that couldn't also count as ends in the circumstances in which they occur: "what is generated by someth ing accidentally is not generated by it in so far as it is of such-and-such a sort, and so in what generates something there 
need not be a likeness of what is generated" just because in cases of accidental generation there isno antecedent likeness of the effect, which is at least often what we would call a chance effect. 67 "For example, the discovery of a treasure has no [antecedent] likeness in the person who finds the treasure accidentally while digging in order to plant something" (In Met. VII: L8.1443). On the other hand, the person's deliberately digging in order to plant something is an agent's acting for an end: it does have an antecedent likeness in the digger's preconception and is an instance of (intellective or artificial rather than natural) agent causation. And if the treasure had been uncovered, instead, by a storm's uprooting a tree, then (natural) agent causation would account only for features of the cause that could be infer red from the effect, such as the direction and force of the wind, forms belonging to $A$ as powers that constitute in $A$ an antecedent likeness of the effect in $\mathrm{P}$, but a likeness that can't be construed as a manifest resemblance of the sort that characterizes an olive tree's generating another olive tree, or yet another tree's being ignited by the flames of a forest fire.

That strongest sort of likeness possible between an effect and its cause considered just as such-substantial-form likeness-is the kind associated with the sort of agent causation that requires the inclusion of the agent cause and its effect within the same species. Biological reproduction is the paradigm but, as we've already seen, not the only instance, since reproductive generation occurs also in non-living things: "if the agent is included in the same species along with its effect, then between the maker and what is made there will be a likeness in form that is in keeping with the same ratio as is associated with the species-for instance, [when] a human being generates a human being" (ST Ia.4.3c), or "when the form of what is generated is antecedently in the generator in the same mode of being, and in similar matter - for instance, when a fire generates a fire" (In M et. VII: L8.1444), or when "heat produces heat" (In Sent. I.8.1.2c).

Aquinas uses the word 'ratio' often and importantly in these discussions in ways that seem to rule out a single fully satisfactory translation for it, mainly because in its various occurrences it conveys a variously proportioned blend of meaning, definition, concept, model, and essential nature. 'Theoretical account' or 'intelligible nature' might come close to being acceptable as a single equivalent, but I'll leave ratio in Latin here, occasionally commenting on what I take to be its sense. In the example of human reproduction in these passages the form is evidently humanity, and the ratio associated with the species is pretty clearly the definiens rational animal, which is necessarily suited to both the agent and its effect because they're both members of the human species. 68

'Mode' is another term used importantly in these passages on samespecies agent causation and elsewhere in Aquinas's account of likeness, causal and otherwise. Sometimes, as here, it picks out the way in which the shared form is realized in the cause and in the effect: flesh and bone in the example of human reproduction. But Aquinas uses 'mode' in this context 


\section{NORMAN KRETZMANN}

also to indicate the degree to which the shared form is realized in the cause and in the effect. In the examples of human beings or olive trees or fires generating others of their kind, the mode in this second sense is essentially just the same, since the ratio is realized completely in both cause and effect.

This strongest sort of causal likeness supports an altogether univocal application of the same species-term both to the agent cause ( which is more conveniently designated ' $C$ ' here) and to its effect, $E$ (where the effect is $P$ 's having been informed with $f$ ). For that reason Aquinas calls this sort of agent causation univocal. The detailed essential likeness of $E$ to its univocal agent cause $C$ and the fact that 'human being,' 'olive tree,' or 'fire' is predicable univocally of both $C$ and $E$ in such cases is founded on three (or four) samenesses: (1) the same form, $f$, is antecedently in $C$ and consequently in $E$; (2) $f$ is associated with the same ratio in both $C$ and $E ; 69$ (3a) $f$ is essentially realized in the same way in both $C$ and $E$, and ( $3 b) f$ is essentially realized to the same degree in both $C$ and $E .70$

O bviously, univocal causation can't be the relationship that accountsfor a fire's hardening clay. The fact that in univocal causation the form shared by $\mathrm{C}$ and $\mathrm{E}$ is realized in the same way and to the same degree is guaranteed by the facts that the relationship between $C$ and $E$ must be the reproductive generation of one member of a species by another member of the same species, and that, consequently, the form that $\mathrm{C}$ and $\mathrm{E}$ share must be their substantial form. But if $C$ and $E$ are not included in a single species, then $E$ doesnot agree with $C$ "in name and ratio. Nonetheless, it's necessary that some likeness be found between them, for it's part of the nature of action that an agent does what is like itself, since each thing acts in keeping with its being in actuality ( secu ndu m qu od actu est) [ - not in a state of mere potentiality]. That's whythe form of the effect is indeed found somehow in a cause that [essentially] surpasses its effect, but in another mode, and in connection with another ratio. And for that reason [such a cause] is called an equivocal cause" (SCG 1.29.270). The fire is an equivocal cause of hardness in the clay ( or of softness in the wax). And if $C$ is an equivocal cause of $E$, then ( 1 ) the same form, $f$, is antecedently in $C$ and consequently in $E$; but ( $\left.2^{\prime}\right)$ it is not the case that $f$ is associated with the same ratio in $C$ and in $E ; 71\left(3 a^{\prime}\right)$ it is not the case that $f$ is essentially realized in the same way in $C$ and in $E$; and ( $\left.3 b^{\prime}\right)$ it isn ot the case that $f$ isessentially realized to the same degree in $C$ and in $E$.

Only the already discounted accidental efficient causation could be purely equivocal (as natural reproductive generation is purely univocal). O nly of accidental efficient causation would it be true also that ( $\left.1^{\prime}\right)$ it is not the case that the same form is antecedently in $C$ and consequently in $E$. Purely equivocal causation is efficient causation by chance as pure equivocation is terminological sameness by chance. ${ }^{72}$ So a fire's hardening clay isn't an instance of pu rely equivocal causation. Adapting Aquinas's use of the sun as his model of an equivocal efficient cause in SCG I.29.270, we can say of the fire that the hardness it causes in the clay must have some sort of likeness not to the fire itself as we ordinarily experience it, but to the fire 
understood in terms of its active powers. The form of hardness that is consequently in the clay is antecedently in that one of the fire's active powers that can be provisionally (and truistically) identified as its clay-hardening power. (And, of course, the form of hardness is antecedently also in the clay's passive potentialities to some extent.73) It's in respect of its active powers that the fire, or any other agent, can be said to be somehow like all its equivocal effects, to possess antecedently, albeit in a different mode, the forms that are found consequently in its equivocal effects. To acquire a more fine-grained understanding of the fire's clay-hardening power is to see more clearly just how the form of hardened clay is antecedently in the fire (and in the clay) - that is, just how fire hardens clay.

So, when we look more closely at Aquinas's account that interrelates likeness and causation, an account he has some right to presuppose at this stage of SCG, we can appreciate and, I think, accept the analogies on which he bases his conclusions in 2.1871: "Therefore, an agent that acts through its [non-intellective] nature [alone] tends toward a determinate end through its own action just as an agent that acts through intellect does. Therefore, every agent acts for an end."

\section{Shortcomings as Evidence of Teleology}

The created world as we know it, including ourselves in several different respects, is undeniably marred by many imperfections or shortcomings of various sorts. Aquinas ingeniously uses this feature of reality (and, even more markedly, of our view of reality) as another basis on which to argue for the universality of his teleology thesis. In his view, the fact that we can't deny the prevalence of failures and flaws is one good reason why we can't avoid thinking teleologically.

Shortcomings are found only in things that are for an end. For if a thing falls short (deficiat) of something it isn't aimed at, that isn't ascribed to it as a shortcoming; if a doctor falls short of healing, that's ascribed as a shortcoming to him, but not to a builder, or a grammarian. (2.1874)

This stage-setting part of the argument calls for a terminological comment. The best efforts of the best doctors do sometimes fall short of healing; and while all such shortcomings may be disappointing, not all of them are avoidable, let alone blameworthy. Still, Aquinas's example suggests, even that sort of unavoidable failure to achieve the agent's end counts as a shortcoming in the agent. 'Shortcoming' is my translation here for 'peccatum.' Because Aquinas also uses 'peccatum' el sewhere for moral fault or sin, someone could think that even in contexts like this one 'peccatum' carries connotations of blameworthiness. ${ }^{74}$ But we'll see, as Aquinas develops his general analysis of badness over the next several chapters of Book III, that he approaches even the 


\title{
118 NORMAN KRETZMANN
}

worst sorts of moral evil as extrapolations from the least troubling sorts of natural defects, including some that are too familiar or too far removed from us to be considered even disappointments. 75 Consequently, in his analysis of badness, shortcoming is the genus of evil, and not conversely. And the rest of this present argument shows that a negative assessment as broad and cool as 'shortcoming' isneeded here, as well.

\begin{abstract}
Now we do find shortcomingsin things that are done in connection with art, as when a grammarian speaksincorrectly. But we also find shortcomings in those that occur in connection with nature, as is clear in cases of congenital deformities ( partubus monstruosis). Therefore, an agent that acts in accordance with nature acts for an end just as truly as an agent that actsin accordance with art and on the basis of a plan. (2.1874)
\end{abstract}

A grammarian's speaking incorrectly is presumably al ways avoidable in theory. If it's being done for pedagogical purposes, it is an utterly undeplorable shortcoming; and if it is being done unconsciously, it is always deplorable, as some of a doctor's shortcomings are not. But from the case of the erring grammarian, which edges closer to blameworthiness, Aquinas moves at once to a much worse sort of shortcoming in what seems to be a very different setting, one that involves no prima facie eligible target of blame. Medical and grammatical shortcomings are artificial, and the agents to whom they are ascribable are readily identified. Congenital deformities are natural, and the agent (or agents) to which they are ascribable is ( or are) not al ways as unmistakably apparent. Against the background built up in SCG so far, it may seem natural to suspect that God himself must be the agent to whom natural shortcomings are to be ascribed. It will of course be very important to discover and assess what Aquinashas to say on that point, but in any event weneither must nor should look immediately for divine agency in things that occur in connection with nature. $76 \mathrm{In}$ reproductive generation, the production of another olive tree is an olive tree's naturallynecessitated effect. And, Aquinas is arguing here, our recognition that a blighted, stunted, sterile, or other wise congenitally defective olive seedling counts as a shortcoming should show us that an olive tree, "an agent that acts in accordance with nature[,] actsfor an end just astruly as an agent that actsin accordance with art and on the basis of a plan"-such as a doctor or a grammarian. The production of another olive tree is a reproducing olive tree's natural lynecessitated effect, but the production of a normal, healthy olive tree isthe natural end of an olive tree in respect of reproductive generation.

\section{Determinate Ends as Necessary Conditions of Action}

Aquinas's final argument in support of III.2's teleology thesis applies more effectively to non-living than to living agents. 
If an agent didn't tend toward any determinate effect, then all effects would be indifferent to it. But what is related indifferently to many things doesn't do one of them rather than another. (It's for that reason that no effect follows from what is contingent in either of two ways unless something determines it to one of them. ${ }^{77}$ ) Therefore, it would be impossible for such a thing to act. Therefore, every agent tends toward some determinate effect, which is called its end. (2.1875)

Buridan's Ass, the untethered donkey that starves to death between two equally tempting piles of hay, each of them precisely ten feet away from the donkey's head, is the paradigm of the sort of agent Aquinas is depicting here: one that is supposed to be incapacitated by an absence of relevant differences among available alternatives. Such force as this argument has stems from its dependence on a version of the Principle of Sufficient Reason.78 But no one believes that a real donkey would behave the way Buridan's Ass behaves in the story-which is obviously meant to lampoon rigid rationality-and rational agents are perhaps even less likely than donkeys to be stymied by options that are equally attractive. As Aquinas himself observes elsewhere,

it depends on the simple volition of the artisan that this stone is in this part of the wall, and that one in another part, even though the nature of his art demands that some stones be in this part and some in that part. (ST Ia.23.5, ad 3)

When the particular alternatives are all equally suitable in all relevant respects, then simply picking at random, rather than rationally choosing, is what's called for. If decision is a component of the process at all, it's exercised by will alone in an act of "simple volition," without any particular input from intellect. So it seems clear that this argument of Aquinas's doesn't show that a theoretical absence of relevant differences among alternatives makes action impossible for intellective agents or even for non-human animals. But it might be said to suggest that in such (very rare) cases something-such as the mason's aim of finishing the wall, or the donkey's aim of getting rid of hunger pangs- has to intervene to bring about action by determining an end. Genuinely incapacitating indifference is much more likely to be found among non-living things. 79

\section{Some Apparent Exceptions}

As I said near the beginning of this consideration of Aquinas's teleology thesis, incognizant natural things make up the biggest and most obviously problematic class of agents to be covered by the thesis. Aquinas has now provided at least a pattern for applying the thesis to any of them, especially 
in 2.1873, discussed in sect. 3 above. But intellective agents like us can provide apparent exceptions of a very different sort, since we may think that introspection provides conclusive evidence that some of the things we do are not done for ends. Aquinas provides three kinds of cases: "contemplative actions," "playful actions," and "actions that are done absentmindedly (absque atten tione), such as rubbing one's beard" (2.1876a).

Suppose I ask you what you're thinking about, and you tell me "irrational numbers," and I ask, "What's the point of that?" You may very well tell me, impatiently, that there's no point to it; it's just what you happen to be thinking about. But that doesn't mean that your thinking in that way is acting for no end since, as Aquinas plausibly claimed earlier, the ends for which some activities are engaged in-intellective and sensory activities especially - are just the activities themselves. 80 And that's what he reminds us of here: "We should know that contemplative actions are not for any other end; instead, they themselves are the end" (2.1876b).

Playful actions haven't been mentioned before, but they don't give him any trouble, either. Suppose that I interrupt you while you're studying and ask you to play a game of checkers, and you agree. And, to guarantee playfulness, suppose that neither of us is interested in or good at checkers, and that we don't care who wins. Is there really some end for which you're acting as you play the game? Aquinas would say that there is, and I think that his affirmative answer again makes plausible use of his distinction between ends of type A and of type B: "playful actions sometimes [B] are an end, when a person plays just for the pleasure there is in playing, and sometimes $[A]$ are for an end, as when we play so that we may study better after wards" (2.1876b). 81

If we think of every movement of our bodies that is under our control as an action of ours, then very many, maybe most, of our bodily actions are absentminded. It's only this one of the three sorts of putative exceptions for which Aquinas supplies an example, and I think his example unfairly helps his case:

actions that are done absentmindedly are brought about not by intellect [of course] but by some unanticipated event in one's imagination (subita imaginatione), or by some natural principle. For instance, a disordering of the [bodily] humor that gives rise to itching is the cause of one's rubbing one's beard, which is done in the absence of intellect's attention. And these actions do tend toward some end, although outside (praeter) the bounds of intellect's ordering. (2.1876b)

The man may not have realized that he was rubbing his beard, much less why he was doing so, until he's asked. But then, surely, he says at once, "Because it was itching." That's too easy. Just because of dealing with this topic, I've been noticing the positions of my hands as I sit back to read what's on the computer screen before I go on typing. I notice that some- 
times they're on the keyboard, sometimes in my lap; sometimes my arms are folded; sometimes I have my right hand on my chin, sometimes my left; etc., etc. I feel as detached from all such actions of mine as I would if I were observing them in someone else, and Aquinas has certainly not provided enough evidence to convince me that every one of these absentminded positionings of my hands is brought about by some unanticipated event in my imagination, or by some natural principle. Of course, if that language of his is taken to be, not implausibly, a thirteenth-century version of the claim that some brain state of mine accounts for those absentminded, ordinarily unnoticed positions of my hands, I would grant it. And in that case, perhaps, I can even see how one might, on the model of Aquinas's explaining fire's hardening of clay as its acting for an end, go on to claim that the purely absentminded positioning of my hands is to be explained as the achieving of the end of some natural process taking place in my body, although, strictly speaking, I can't be identified as the agent of that action. 82 That is, some movements made by an intellective agent that give the appearance of deliberate actions, and that in other circumstances certainly could be deliberate actions, may nevertheless be not the actions of an intellective agent considered just as such but merely naturally necessitated effects of natural principles and processes in the agent's body. The passage quoted just above, in which Aquinas tries to deal with absentminded movements, contains suggestions that might be developed along such lines. But if he had any such developments in view, he ought not to have used as his only example absentmindedly rubbing a beard that itches.

It's a little surprising that Aquinas develops and defends his teleology thesis along the lines we've been examining without even mentioning final causation. But in III.2's final sentence, it emerges as a concept that he has of course recognized as supplying one way in which to read the thesis: "N ow on this basis we rule out a mistake made by ancient natural philosophers, who claimed that all things happen because of matter's necessity, entirely removing the final cause from things" (2.1877). 83 Aquinas casts this development and defense of the thesis in terms of agents, actions, and ends because those terms are more exactly suited to the purposes of his project in SCG III than is the more abstract 'final causation.'

\section{Every Agent's End is Good}

Aquinas introduces the thesis of III.3 as something that must be taken up at this stage: "N ow on that basis we have to show, further, that every agent acts for what is good" (3.1878). It might occur to someone that this is what Aquinas has to show, further, because he's dealing "first, with God himself in so far as he is the end of all things" (1.1867b), and what he's shown in the preceding chapter, III.2, is that all things do act for an end. Since that end must eventually be shown to be God, there's progress to 
be made in showing, further, that what every agent acts for is something good. But that interpretation of this particular move would be mistaken in two ways.

In the first place, there's a scope-ambiguity in the teleology thesis that forms the basis for this new thesis. 'Every agent intends some end' may be read either as (I) 'For every agent, $x$, there is some end, $y$, such that $x$ intends $y$ ' or as (II) 'There is some end, $y$, such that for every agent, $x, x$ intends y.' (I) is clearly the interpretation that has been at issue in III.2, and anyone prepared to say that Aquinas has at least made considerable progress in developing and defending his teleology thesis will also be taking interpretation (I) for granted. However, although interpretation (I) is the one at issue so far, and although it's much less implausible than (II), it certainly does look as if Aquinas will need to establish (II) eventually on his way to showing that God himself is the one and only end of all things. And there's a related ambiguity in the goodness thesis of III.3 that can, on one interpretation, make it look like a bold move in the direction of (II). For 'omneagens agit propter bonum' might be read not merely as 'every agent acts for what is good' or '. . . a good' or '. . . something good,' but, more narrowly, as 'every agent acts for the good' or even '. . . goodness.'

But, in the second place, Aquinas's development and defense of the goodness thesis in III.3 shows unmistakably and from its very beginning that at this stage he intends only the first and less implausible of those two interpretations of it.84

In his first argument for the goodness thesis Aquinas reveals not only what he means by it but also how he understands it to be based on the teleology thesis. "For the fact that any and every agent tends toward something determinate makes it clear that every agent acts for an end. But that toward which an agent tends determinately must be appropriate (conven iens) for it, since the agent wouldn't tend toward it if it weren't somehow appropriate for itself. But whatever is appropriate for anything is good for it. Therefore, every agent acts for something good" (3.1879). It is, of course, this argument's use of 'appropriate for it,' 'appropriate for itself,' and, most directly, 'good for it' that show clearly that Aquinas intends the goodness thesis in its more plausible sense. The argument's first premise might be read as implying that Aquinas takes the argument from determinateness to be the most effective support for the teleology thesis, which would be surprising. 85 But I think he uses it here just because it strikes him as providing the most convenient basis on which to make the transition to the goodness thesis. The fact, if it is a fact, that societies and other systems tend toward disorder doesn't constitute a counter-instance to the strong claim in the first premise. Systems may not count as agents, even under Aquinas's very broad notion of an agent. More importantly, even disorder itself is not indeterminacy but may be considered a determinate end toward which a thing (or an arrangement of things) can tend determinately.

Clear and helpful though this first argument is, it raises a problem that 
is apparently deepened by developments later in the chapter. For, aside from separated or purely intellective substances, every created thing, including every human being, eventually dies or other wise ceases to exist.86 'Simple corruption' is Aquinas's generic designation for the end of individual creaturely existence: "All corruption occurs through a separation of form from matter-simplecorruption through the separation of the substantial form, of course, but corruption in a certain respect through the separation of an accidental form" (II.55.1298). Coffee's cooling or clay's hardening is corruption of the coffee or the clay in a certain respect as a human being's dying, the separating of the soul from the body, is simple corruption. Because all material created things are constantly subject to corruption in a certain respect and eventually succumb to simple corruption, it seems right to say that every material created thing tends toward its own corruption, which is something determinate. Against that background, look again at these sentences from the argument we're considering: "But that toward which an agent tends determinately must be appropriate for it, since the agent wouldn't tend toward it if it weren't somehow appropriate for itself. But whatever is appropriate for anything is good for it" (3.1879). Now Aquinas emphatically denies that the corruption of any thing is good for that thing. As he says later in this same chapter, "all natural agents, to the extent of their power, resist corruption, which is bad for each and every thing" (3.1885).87 If any thing's corruption is bad for it, and if every material created thing tends toward its own corruption, then it isn't true that "that toward which an agent tends determinately must be appropriate for it." 88

What's gone wrong here? It's not that Aquinas thinks that an agent can't tend toward and resist the same thing at the same time, since he of course believes that a person can resist temptation. 89 And I can't see how 'ten ds determinately' might make the crucial difference, since there's nothing indeterminate about an agent's simple corruption or about its tending toward that end. Nor do I think that I've created the problem by interpreting 'tends toward' too broadly, since Aquinas's use of that term here must cover all the naturally necessitated tendencies of non-living agents as well as the deliberated, freely chosen plans of intellective agents. Still, what a thing tends toward does seem to include the actualizing of its passive potentialities as well as of its active powers, and the natural corruption of a thing, especially its simple corruption, results essentially from the actualizing of some of its passive potentialities rather than being brought about by its exercising its active powers. So perhaps this problem is caused by Aquinas's use of 'tends toward' here rather than, say, 'acts for,' another term he often uses in this context.90

I want to consider just two others of the nine arguments supporting the goodness thesis in III.3. The seventh argument provides simple but effective support for the thesis by drawing on the notion of badness, which occupies Aquinas's attention over the next thirteen chapters. ${ }^{91}$ 
Avoiding what is bad and seeking what is good have the same nature, in the same way as moving down and moving up have the same nature. ${ }^{92}$ But we find that all things avoid what is bad. For things that act through intellect avoid something because they apprehend it as bad, while all natural agents, to the extent of their power, resist corruption, which is bad for each and every thing. Therefore, all things act for something good. (3.1885)

Things that act through intellect, including us, may sometimes, at their best, avoid what they apprehend as bad for future generations, or bad absolutely, even though advantageous for themselves. But each of them must, if the individual is to survive, avoid on most occasions what the individual apprehends as bad for itself. And since corruption "is bad for each and every thing," and since a human being's avoidance of corruption entails eating, and since eating entails the corrupting of something else, an agent's avoiding of what is bad for itself will often entail not merely its seeking what is good for itself but, thereby and at the same time, what is bad for something else. However, as we've seen in discussing Aquinas's broad and cool sense of 'peccatum,'93 and as I discuss in detail in Chapter III below, his analysis of badness is characterized throughout (quite properly, I think) by clinical detachment-an approach that provides grounds for rationally accepting certain sorts of badness even while acknowledging their badness. Not surprisingly, this approach is less easy to appreciate at the level of moral judgment than at the metaphysical level. But, as we'll see, the analysis develops from the metaphysical level, where we begin by understanding that "every actuality has the defining characteristic of goodness (boni) , since badness (malum) is found only in a potentiality that falls short of actuality" (3.1883),94 and that the generation of any one thing involves the corruption of another, 95 and that for ver y many things, including us, their preservation involves the destruction of very many other things.

As Aquinas's seventh and fifth arguments in defense of his goodness thesis introduce the notion of badness, so the eighth introduces the notion of chance, which is also important in his consideration of providence in Book III.

Whatever results from any agent's action but is apart from ( praeter) the agent's intention is said to happen by chance or fortune. Now in the works of nature we observe that what is for the better is what happens either always or usually (frequentius). For instance, in plants the leaves are arranged in a way that protects the fruit, and the parts of animals are disposed so that the animal can protect itself. Therefore, if this sort of thing happens apart from the intention of a natural agent, it will be by chance or fortune. But that's impossible, since it is not things that happen al ways or often (frequenter) that are by chance or fortuitous, but rather those that happen very seldom (in paucioribus) [Physics II 5, 196b10-17]. Therefore, a natural agent tends toward what is for the 
better. And, much more obviously, so does one that acts through intellect. Therefore, every agent in acting intends something good. 96 (3.1886)

The value of this argument, as I see it, lies not in the support it provides for the goodness thesis but in what it tells us about Aquinas's notion of chance. It presents two aspects of that notion: (1) what results from any agent's action but is apart from the agent's intention happens by chance; (2) what happens by chance happens very seldom. (1) looks too broad and too strong to be true. What about the practical joker who really didn't intend to injure his victim by pulling her chair out from under her as she was sitting down? Would Aquinas really be prepared to say that her injuries are just bad luck? No, as he shows later, when he refines (2), the frequency condition, in a way that affects (1) and limits the range of acceptable excuses:

it's important to know that not everything that is apart from intention must be fortuitous or by chance. ... For if what is apart from intention is something that always or often results from what is intended, then it will not happen fortuitously or by chance. For instance, in the case of a person who intends to enjoy the sweetness of wine, if drunkenness follows from the drinking of the wine, that will not be fortuitous or by chance. If that resulted in [only] a few cases, however, then it would be by chance. 97 (III.5\&6.1902)

As for (2), what happens by chance happens very seldom, it's clearly more fundamental to his notion than (1) is, as can be seen in the later passage just quoted. And it seems unobjectionable. If lightning strikes the same spot always or very often, then we'll look for a causal explanation of a result that we're not in those circumstances prepared to describe as chance. But in applying his notion of chance to phenomena of natural selection, Aquinas seems to be making a mistake in reasoning. He cites the facts that in plants the leaves are arranged al ways or usually in a way that protects the fruit, and that the parts of animals are disposed al ways or usually so that the animal can protect itself. But these facts could, for anything Aquinas says here, result from a unique chance mutation in the past that was advantageous for the individual plant or animal in which it occurred-a mutation such that the progeny of those individuals had an advantage in surviving and reproducing, with the result that the once-unique, chance characteristic is now found in members of those species always or usually. 98

O ne reason for thinking that this criticism may not apply so neatly to this argument is that, immediately after introducing those examples of natural goods, Aquinas says that "if this sort of thing happens apart from the intention of a natural agent, it will be by chance or fortune." Since 'a natural agent' could just as readily be translated as 'the natural agent,' other 


\section{NORMAN KRETZMANN}

things being equal, someone might be inclined to think that Aquinasishere alluding to God as the governor of his creation. But since 'agens naturale' in this discussion has until now meant some created natural agent, that would constitute a very surprising and confusing shift in Aquinas's terminology. 99 Besides, in this case other things are not equal, as can be seen from the way Aquinas distinguishes between natural and intellective agents at the and of the argument: "Therefore, a natural agent tends toward what is for the better. And, much more obviously, so does one that acts through intellect." And God, of course, is the paradigmatic, perfect intellective agent.100

\section{BADNESS}

\section{The Badness Thesis}

'Badness' is not a good word. It sounds faintly infantile, perhaps especially now, at the end of the twentieth century. Still, 'imperfection' and its bland companions are too broad to serve all the purposes of this investigation, while 'evil,' 'wickedness,' 'immorality,' 'sinfulness,' and the like are even more clearly too narrow. 'M alum' is almost the only word Aquinas uses, adjectivally or as a nominalized adjective, for the central notion in III.4-15, a series of chapters that has sometimes been called a treatise de malo.101 And 'bad' and 'badness' are the only English words that strike me as coming close to playing all the roles Aquinas assigns to 'malum.' With that semi-satisfactory bit of terminological equipment we can start an investigation of his treatise on badness.

It begins in III.4 with what I'II call the badness thesis: "Now on that basis it is apparent that the badness in things, events, or states of affairs occurs apart from the intention of their agents (Ex hoc autem apparet quod malum in rebus incidit praeter intentionem agentium)" (3.1889). I've expanded Aquinas's one word 'rebus' into the phrase 'things, events, or states of affairs.' It's usually translated most safely as 'things,' but I think that the generality implicit in it needs to be spelled out in that way here, and occasionally elsewhere. Aquinas's reference to "the badness in things, events, or states of affairs" rather than merely badness for the agent appears to generalize and objectify the kinds of badness at issue. The introductory formula 'on that basis,' al ready familiar from the beginnings of many earlier chapters in SCG I-III, refers in this case to the goodness thesis for which he argued in the preceding chapter. If, as his first formulation of the goodness thesis maintains, "every agent acts for what is good," then no agent acts for what is bad; and so the badness that does undeniably mar many things, events, and states of affairs can't be what their agents act for; it must therefore occur apart from their agents' intention. Viewed in this way, the 